\title{
A Psicologia do Trânsito e os 50 Anos de Profissão no Brasil
}

\author{
Traffic Psychology And 50 Years \\ Of Profession In Brazil
}

La Psicología Del Tránsito Y

Los 50 Años De Profesión En El Brasil

Fábio Henrique Vieira de

Cristo e Silva

Universidade de Brasília

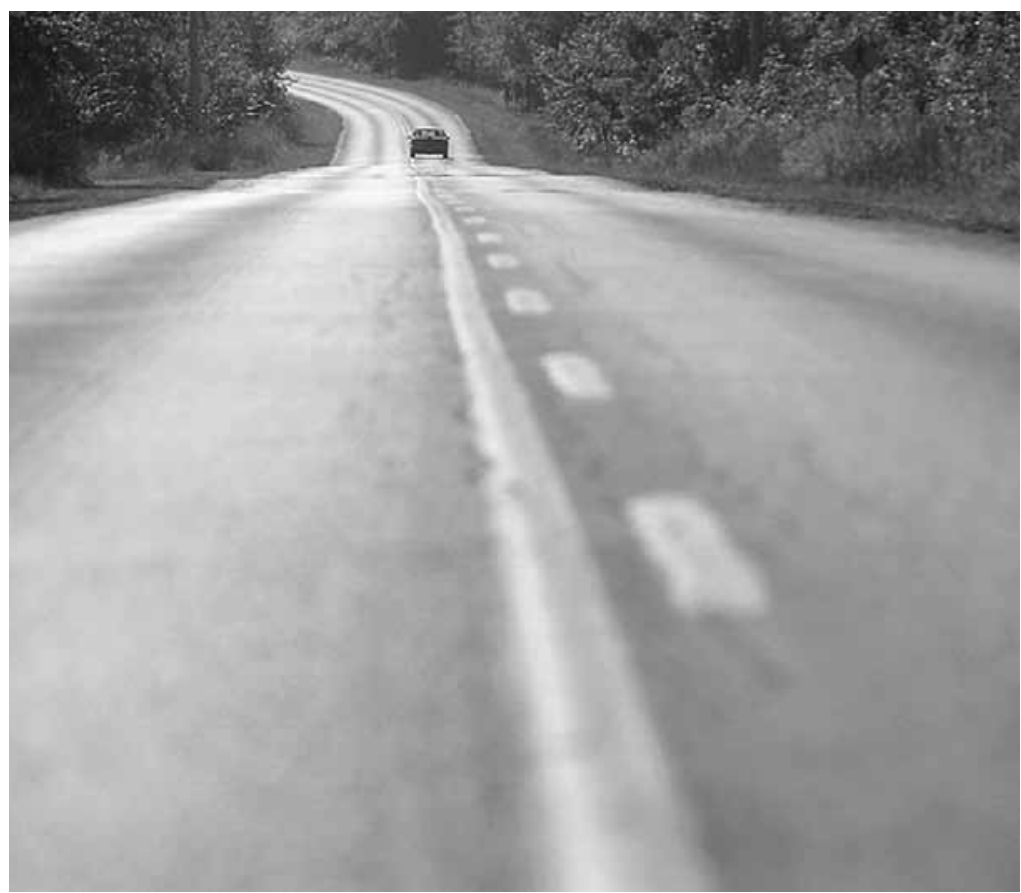


Resumo: Em 2012, a Psicologia completa 50 anos como profissão reconhecida no Brasil, sendo esse um momento oportuno para pensar e repensar a prática do psicólogo em suas diversas áreas. Neste artigo, analisase especificamente o desenvolvimento histórico da Psicologia do trânsito, sendo abordados acontecimentos históricos pré e pós-regulamentação da Psicologia, como a promulgação de leis, resoluções e suas respectivas alterações, a criação do Conselho Federal, dos Conselhos Regionais e da Associação de Psicologia do Trânsito, além da discussão sobre o veto presidencial à avaliação psicológica em futuros motoristas. Como conclusão, cita-se algumas iniciativas que devem ser comemoradas pela categoria, como a ampliação das oportunidades de formação profissional (cursos de perito e especializações), a participação da Psicologia em instâncias consultivas e decisivas das políticas de trânsito e os esforços do Conselho Federal para discutir e qualificar as ações dos profissionais com a elaboração de referências técnicas, a organização de debates, seminários e publicações. Sugere-se, ainda, iniciativas que devem ser aprimoradas nos próximos anos, como, por exemplo, a ampliação da discussão sobre políticas públicas de mobilidade urbana durante a graduação e a pós-graduação, a participação ativa (individual e coletiva) nos movimentos sociais sobre o tema e o modelo de atuação profissional, que incorpore outros paradigmas.

Palavras-chave: Atuação do psicólogo. Avaliação psicológica. Psicologia do trânsito. Políticas públicas. História da Psicologia-Brasil.

Abstract: In 2012, psychology will be 50 years as a recognized profession in Brazil and this is an opportune time to think over the practice of psychologists in various areas. This article examines specifically the historical development of traffic psychology and the historical events discussed pre- and post-regulation of psychology, such as the enactment of laws, resolutions and their amendments, the creation of the Federal Council, Regional Councils and the Association of Traffic Psychology, besides the discussion of the presidential veto in psychological assessment for future drivers. In conclusion we quote some initiatives that should be celebrated by the category, such as the expansion of training opportunities (courses, expertise and specializations), participation in advisory bodies of psychology and decisive policy of transit, and the efforts of the Federal Council to discuss and describe the actions of professionals with the preparation of technical references, organizing debates, seminars and publications. We also suggest initiatives that should be improved in the coming years, for example, the expansion of the discussion on policies for urban mobility during undergraduation and graduation, active participation (individual and collective) in social movements on the subject and the professional role model, that incorporates other paradigms.

Keywords: Psychologist performance. Psychological evaluation. Traffic psychology. Public policies. History of psychology- Brazil.

Resumen: En 2012, la Psicología completa 50 años como profesión reconocida en el Brasil, siendo ése un momento oportuno para pensar y repensar la práctica del psicólogo en sus diversas áreas. En este artículo, se analiza específicamente el desarrollo histórico de la Psicología del tránsito, siendo abordados acontecimientos históricos pre y pos-reglamentación de la Psicología, como la promulgación de leyes, resoluciones y sus respectivas alteraciones, la creación del Consejo Federal, de los Consejos Regionales y de la Asociación de Psicología del Tránsito, además de la discusión sobre el veto presidencial a la evaluación psicológica en futuros conductores. Como conclusión, se citan algunas iniciativas que deben ser conmemoradas por la categoría, como la ampliación de las oportunidades de formación profesional (cursos de perito y especializaciones), la participación de la Psicología en instancias consultivas y decisivas de las políticas de tránsito y los esfuerzos del Consejo Federal para discutir y calificar las acciones de los profesionales con la elaboración de referencias técnicas, la organización de debates, seminarios y publicaciones. Se sugieren, asimismo, iniciativas que deben ser perfeccionadas en los próximos años, como, por ejemplo, la ampliación de la discusión sobre políticas públicas de movilidad urbana durante la graduación y la posgraduación, la participación activa (individual y colectiva) en los movimientos sociales sobre el tema y el modelo de actuación profesional, que incorpora otros paradigmas.

1 Agradecimentos a Lílian de Cristo pelos comentários e sugestões

úteis na versão preliminar deste artigo. Este trabalho

contou com o apoio financeiro do CNPq por meio de bolsa de doutorado.

Palabras clave: Actuación del psicólogo. Evaluación psicológica. Psicología del tránsito. Política pública. Historia de la Psicología- Brazil.

O ano 1962 foi especial para a Psicologia brasileira. O Presidente João Goulart promulgava, a 27 de agosto, a Lei no 4.119, que dispõe sobre os cursos de formação em Psicologia e regulamenta a profissão de psicólogo. A partir dessa política, a Psicologia entrou no rol das profissões reconhecidas em nosso país, sendo definido com maior clareza o seu campo de ação profissional. O documento legitimou, do ponto de vista legal, as práticas psicológicas já existentes até aquele momento, impulsionadas por 
suas importantes aplicações às necessidades nos diversos setores da vida social, como educação, saúde, trabalho e transporte (Antunes, 2001). Passados 50 anos, é hora de pensar e de repensar a nossa prática profissional, a fim de planejarmos as próximas décadas, considerando erros e acertos ao longo do caminho. Neste artigo, analisa-se o desenvolvimento histórico da Psicologia do trânsito nos períodos pré e pósregulamentação da Psicologia como profissão no Brasil. Serão apresentados e discutidos alguns acontecimentos internos e externos à Psicologia, documentos legais e ações coletivas dos psicólogos que, de alguma forma, constituíram, de modo específico, o trabalho do psicólogo do trânsito e que, de modo geral, ajudaram a compor o cenário atual da Psicologia em nosso país. Especial atenção será dada à avaliação psicológica de motoristas, tendo em vista que é um trabalho realizado por muitos profissionais na seara do trânsito e que possui raízes históricas fortes no campo que denominamos Psicologia do trânsito. Ao final, sugere-se o quê comemorar em 2012 e o quê aprimorar nos próximos anos para tornar a Psicologia do trânsito cada vez mais útil à sociedade.

\section{Período pré-regulamentação da profissão}

Os conhecimentos psicológicos se inseriram no trânsito rodoviário de diversas formas, dentre elas, de leis que expressaram políticas de segurança e prevenção. Algumas delas, por sua vez, tinham - como ainda hoje têm - a finalidade de identificar e restringir, no decorrer do processo de aquisição da Carteira Nacional de Habilitação $(\mathrm{CNH})$, o acesso ao volante das pessoas consideradas propensas, do ponto de vista psicológico, a se envolver em acidentes de trânsito. A raiz dessa política encontra-se em décadas anteriores à regulamentação da Psicologia no País.
A primeira legislação que tratou do tema no Brasil foi promulgada em 1910 (Decreto-lei ${ }^{\circ}$ 8.324), com a aprovação do regulamento para o serviço de transportes de passageiros ou mercadorias por automóveis. Esse documento, dentre outros assuntos, estabelecia as medidas de segurança que os motorneiros (como eram chamados os motoristas) deveriam seguir, as penalidades e a fiscalização. Um dos artigos sinalizava o que já era uma preocupação naquele momento, e que seria, posteriormente, um grande desafio para a Psicologia do trânsito no Brasil, notadamente no período da sua inserção nesse contexto, o motorista: "O motorneiro deve estar constantemente senhor da velocidade de seu vehiculo, devendo diminuir a marcha ou mesmo parar o movimento, todas as vezes que o automóvel possa ser causa de acidentes" (Departamento Nacional de Trânsito - DENATRAN, 2010, p. 20).

Um marco legal que estabeleceu explicitamente as bases para a futura prática do psicólogo no contexto do trânsito foi o primeiro Código Nacional de Trânsito (Decreto-lei $n^{\circ} 2.994 / 1941$ ), que estabeleceu os exames para obter a licença de praticagem ou de habilitação para condutor de veículo: fisiológico ou médico e psicológico. Nesse último exame, o candidato poderia ser "recusado" por não apresentar o mínimo "perfil psico-fisiológico" exigido. A partir disso, instituíram-se verificações periódicas das condições mínimas de capacidade física e psíquica dos motoristas; dessa forma, esperava-se contribuir de maneira preventiva, isto é, não permitindo que pessoas consideradas propensas a se envolver em acidentes (inaptas) tivessem acesso ao volante (ver na Tabela 1 um histórico dos nossos códigos de trânsito e de suas respectivas alterações).

Oito meses depois, um novo decreto-lei, $\mathrm{n}^{\circ}$ 3.651, alterou o referido código em algumas partes, criando o Conselho Nacional de 
Trânsito (CONTRAN), órgão máximo normativo e consultivo que coordena atualmente o Sistema Nacional de Trânsito (SNT), responsável pela elaboração das regulamentações em forma de resolução, muitas delas com impacto no trabalho do psicólogo (Brasil, 1941). Outra mudança importante ocorreu na seção dos exames para a habilitação. A avaliação dos aspectos psicológicos seria realizada apenas em uma circunstância específica. O art. 108 indicava que, no caso de acidente grave na via pública e apurada a culpa do condutor, este seria submetido a novo exame de visão, e, ainda, ao exame psicofisiológico se decorridos mais de dois anos a contar do último a que havia sido submetido. Tal medida fez perder o caráter preventivo do exame psicológico, conforme proposto inicialmente, para o candidato adquirir a habilitação. De certa forma, esse pode ser considerado o primeiro veto à avaliação psicológica no processo de habilitação, ou, então, um prenúncio do veto presidencial que ocorreu muitos anos depois, na década de 90, conforme será discutido adiante.

Tabela 1. Códigos de trânsito instituídos no Brasil e suas alterações

\begin{tabular}{|c|c|}
\hline Códigos & Assuntos e alterações \\
\hline $\begin{array}{l}\text { Código Nacional } \\
\text { de Trânsito } \\
\text { (1941) }\end{array}$ & $\begin{array}{l}\text { Decreto-lei no 2.994, de } 28 \text { de janeiro de 1941: institui o Código } \\
\text { Nacional de Trânsito } \\
\text { Decreto-lei no 3.651, de } 25 \text { de setembro de 1941: dá nova } \\
\text { redação ao Código Nacional de Trânsito } \\
\text { Decreto-lei no 9.545, de } 05 \text { de agosto de 1946: dispõe sobre a } \\
\text { habilitação e o exercício da atividade de condutor de veículos } \\
\text { automotores }\end{array}$ \\
\hline $\begin{array}{l}\text { Código Nacional } \\
\text { de Trânsito } \\
\text { (1966) }\end{array}$ & $\begin{array}{l}\text { Lei no } 5.108 \text {, de } 21 \text { de setembro de 1966: institui o Código } \\
\text { Nacionalde Trânsito } \\
\text { Decreto no } 86.714 \text {, de } 10 \text { de dezembro de 1981: promulga a } \\
\text { Convenção sobre Trânsito Viário. O Brasil aderiu à Convenção sobre } \\
\text { Trânsito Viário de Viena }\end{array}$ \\
\hline
\end{tabular}

Código de

Trânsito

Brasileiro (1997)
Lei no 9.503, de 23 de setembro de 1997: institui o Código de Trânsito Brasileiro

Lei no 9.602, de 21 de janeiro de 1998: dispõe sobre legislação de trânsito e dá outras providências (com a queda do veto, esta lei inclui novamente a obrigatoriedade da avaliação psicológica no processo de habilitação)

Lei no 10.350, de 21 de dezembro de 2001: altera a Lei no 9.503, de 23 de setembro de 1997 - Código de Trânsito Brasileiro, de forma a obrigar a realização de exame psicológico periódico para os motoristas profissionais

Ainda na década de 1940, foi promulgado outro decreto-lei, $n^{\circ} 9.545$, que causou impacto na futura profissão de psicólogo, que abordava a habilitação e o exercício da atividade de condutor de veículos automotores, indicando as normas para o exame médico (físico e mental) de candidatos a condutor de veículos (Brasil, 1946). O documento informava explicitamente que deveria ser 
organizado um conjunto de testes para o exame psíquico, a critério da junta médica, sem caráter eliminatório, até que fossem estabelecidas as "médias normais" do perfil psicofisiológico do condutor do veículo.

Esse perfil psicofisiológico, todavia, nunca foi de fato estabelecido, apesar das tentativas de se estabelecer critérios de tomada de decisão para o psicólogo, por exemplo, com o estabelecimento de percentis mínimos e tetrons (CONTRAN, 1998a). Esse perfil é essencial para uma avaliação mais adequada de motorista, e sempre foi reivindicado pelos profissionais. Nem as autoridades, nem os psicólogos tomaram para si a realização desse árduo, porém imprescindível, empreendimento.

Em resumo, na década de 40, temos, portanto, a expressão das primeiras políticas nacionais de segurança no trânsito, por meio de decretos-lei que provocaram impacto na futura profissão de psicólogo, ainda por ser regulamentada.

Na década de 50, o governo de Juscelino Kubitschek (1956-1961) impulsionou a indústria automobilística e a construção de rodovias que interligavam o País, orientado por sua política de modernização e de interiorização (Lima Neto, 2001). Como reflexo, o automóvel começava a receber incentivo para sua aquisição e uso como principal meio de transporte.

No âmbito da Psicologia, foram produzidas as primeiras reflexões sobre a seleção psicotécnica de motoristas e sua importância na diminuição dos acidentes de trânsito, assim como a elaboração dos primeiros critérios e normas para a população brasileira nos diversos testes usados para a habilitação (Amorim, 1953; Antipoff, 1956; Campos, 1951; Nava, 1957; Nava \& Cunha, 1958; Silva \& Alchieri, 2007, 2008). Esse período pode ser caracterizado como uma época importante especialmente no âmbito da avaliação psicológica de motoristas, pois começava-se a tentar estruturar o que seria o perfil psicofisiológico indicado outrora. A Psicologia também se deparou com os primeiros dilemas e críticas concernentes a essa área: o seu elevado custo e o prejuízo causado com o afastamento do motorista do seu meio de vida, sem direito ao recebimento de aposentadoria quando considerado inapto, o tempo necessário para a reavaliação do candidato inapto (que era de quatro meses), as imprecisões dos critérios para se definir um candidato apto/inapto e a necessidade de diferenciação nos critérios e no modo de avaliar os motoristas de acordo com a categoria de veículo pretendida (Vieira, Pereira, \& Carvalho, 1953). Alguns desses aspectos, ainda hoje, também são problemáticos na prática do psicólogo perito em trânsito, como a reavaliação do inapto que, em geral, é de 15 dias, ou ainda a necessidade de sistematização das habilidades mínimas dos motoristas que utilizam o veículo automotor para atividade remunerada e para atividades não remuneradas, para fins de avaliação (Conselho Federal de Psicologia CFP, 2009b).

Em suma, a década de 50 representou a expansão da seleção psicotécnica e dos instrumentos. Estabeleciam-se as bases para a regulamentação da profissão de psicólogo. Mas, como a Psicologia do trânsito trilhou seu caminho após essa regulamentação?

\section{Período pós-regulamentação da profissão}

Até meados da década de 60, as ações do Estado brasileiro relativas às políticas de desenvolvimento urbano e de transporte urbano, conforme o Instituto de Pesquisa Econômica Aplicada (IPEA), caracterizaramse por serem "(...) desarticuladas, aplicadas por diferentes setores do governo, sem 
diretrizes ou estratégias básicas de ação no meio urbano" (2010, p. 567). Essa era uma época de conturbações e de amplas reformas administrativas entre os governos militares, que deram continuidade ao desenvolvimento do sistema rodoviário que se delineara nas décadas anteriores (Cristo, 2011).

Em 1962, a profissão de psicólogo foi regulamentada no Brasil, dando início ao movimento de criação do Conselho Federal (CFP) e dos Conselhos Regionais de Psicologia (CRPs). A Psicologia do trânsito configurou-se como uma das primeiras áreas de atuação do psicólogo desde o início do reconhecimento da Psicologia no País.

Alguns anos depois, no âmbito da legislação de trânsito, foi instituído o segundo Código Nacional de Trânsito (Brasil, 1966). Essa lei reorganizou o SNT e, dentre outras coisas, criou os Departamentos de Trânsito (DETRANs) como parte desse sistema. Cada Estado brasileiro deveria implantar o seu próprio DETRAN, o que ocorreu principalmente entre as décadas de 60 e 70 (Cristo, 2011; Silva \& Günther, 2009). Dentro de sua estrutura, deveriam ser instituídos obrigatoriamente os serviços psicotécnicos. Os psicólogos - agora reconhecidos como tal-se inseriram efetivamente no processo de habilitação dentro dos DETRANs, realizando o exame psicotécnico em candidatos à habilitação. A década de 60 caracterizouse, portanto, pela organização políticoadministrativa de categoria dos psicólogos, e também pela institucionalização e expansão da Psicologia nos diferentes espaços de atuação, dentre eles, os DETRANs, consolidando as raízes identificadas desde o período pré-regulamentação.

Na década de 70, no campo da Psicologia, é interessante destacar os estudos do professor Reinier Rozestraten sobre a percepção em campo aberto, que o levaram a estudar a legibilidade das placas rodoviárias, e o levou ao desenvolvimento da Psicologia do trânsito enquanto subárea da psicologia. Em suas palavras: "Começamos então um estudo extenso, de mais de dois anos, sobre a legibilidade das placas rodoviárias, mais por razões didáticas do que para descobrir muita coisa nova" (1988a, p. 128). O trabalho não tinha o objetivo explícito de colaborar com políticas públicas de segurança, tampouco era decorrente delas; todavia, estabeleceram-se contatos com outras áreas, como a Engenharia, e com instituições, como o Departamento de Estradas de Rodagem (DER) de Ribeirão Preto, SP. Dessa forma, o professor se dava conta da dimensão comportamental no trânsito quando disse, em um evento:

Tomamos consciência do fato de que
o trânsito resulta do comportamento
humano, eque esse tipo de comportamento
está entre os mais perigosos, uma vez que
causa a morte anualmente de 50.000
brasileiros, dentre os quais 5.000 crianças.
A percepção é um componente importante
desse comportamento. Em consequência
disso, realizei um estágio no Laboratoire
de la Conduite (...) (Rozestraten, 1988a,
p. 128)

Suas pesquisas lançaram as bases para a estruturação da Psicologia do trânsito no Brasil na década seguinte, implementada por ele mesmo após sua volta do estágio de pós-doutorado na França (1979-1980), com a publicação do livro Psicologia do Trânsito: Conceitos e Processos Básicos (Rozestraten, 1988b), além das publicações sobre os sinais de trânsito e o comportamento seguro (e.g., Rozestraten \& Dotta, 1996).

A década de 80, no plano nacional, caracterizou-se pela redemocratização e pela promulgação da Constituição de 1988. Nesse documento, destacam-se os artigos que estabelecem o direito à livre locomoção, aos serviços de transporte de passageiros e ao transporte escolar. No período, foi promulgada, ainda, a Convenção sobre o Trânsito Viário (Brasil, 
1981), um documento que foi produto de uma convenção internacional celebrada em Viena, em 1968, à qual o Brasil veio a aderir somente anos depois. Os países contratantes se comprometeram a facilitar o trânsito viário internacional e a aumentar a segurança nas rodovias pela adoção de regras de trânsito uniformes.

No contexto acadêmico, com a volta de Rozestraten ao Brasil, a área tomava novo fôlego com a criação, pelo pesquisador, do primeiro grupo de pesquisa em Psicologia do trânsito, em 1983, na Universidade Federal de Uberlândia. Esse grupo organizou congressos brasileiros de Psicologia do trânsito, criou um periódico científico específico, a revista Psicologia: Pesquisa \& Trânsito, atualmente inativa ${ }^{2}$ (Spagnhol, 1985), elaborou um guia internacional de pesquisas em Psicologia do trânsito (Rozestraten, 1982) e ofereceu as primeiras disciplinas na graduação e os primeiros cursos de especialização específicos da área. Também foram publicados trabalhos importantes estruturando a Psicologia do trânsito com foco em todos os seus participantes, seja criança, jovem, adulto ou idoso; motorista, passageiro, pedestres ou ciclistas (Rozestraten, 1981, 1983, 1988b), em interface com várias áreas da Psicologia e de outros campos do saber (Rozestraten, 1985), ampliando a visão da psicotécnica aplicada ao motorista de outrora.

Em 1982, foi realizado o Primeiro Congresso Brasileiro de Psicologia do Trânsito, em Porto Alegre, sendo o ponto de maior destaque a fundação da Associação Brasileira de Psicologia do Trânsito (ABRAPT), cujo primeiro presidente foi o Dr. Enis Rey Gil. A partir dessa associação, a Psicologia do trânsito teve voz ativa e influente na elaboração de documentos que mais tarde embasariam políticas nacionais de segurança no trânsito. Como exemplo, destaca-se a participação nas reuniões de trabalho em prol da segurança de tráfego, que foram promovidas pelo Ministério dos Transportes, em 1985. Vários representantes de entidades participaram dessas reuniões, e um dos resultados foi a publicação do livro O Acidente de Tráfego: Flagelo Nacional Evitável (Empresa Brasileira de Planejamento de Transportes, 1987), que sintetizou o conhecimento disponível e as formas de o Brasil enfrentar os acidentes. Atualmente, a ABRAPT está inativa, embora não falte interesse de vários profissionais e de pesquisadores em criar outra associação. Se esse anseio se tornar realidade, terá este exemplo como modelo para inspirar novamente uma participação ativa na formulação de políticas públicas de trânsito.

Ainda nessa época, a Psicologia rediscute o seu papel frente aos problemas do trânsito e o trânsito como expressão do uso do espaço urbano, um avanço para a época, discussão que foi aprofundada nas décadas seguintes. O número especial da revista do Conselho Federal de Psicologia (1986), por exemplo, debateu o tema:

Segundo especialistas da área, os acidentes fatais no trânsito são de tal magnitude que estão se constituindo em problema epidemiológico. A sociedade como um todo sensibiliza-se para essa questão, e o CPF assume a discussão. A prática predominante dos psicólogos na área do trânsito é a da aplicação dos exames psicológicos para seleção de candidatos à carteira de habilitação. Será essa uma boa forma de contribuir para minorar os graves problemas do trânsito? Há outras alternativas de atuação? (p.18)

Em suma, a década de 80 foi uma época de grande preocupação com a segurança no trânsito, o que foi expresso, por exemplo, na organização dos primeiros eventos nacionais nas diversas áreas, como Psicologia, Medicina, educação, Engenharia e legislação de trânsito. Além disso, a Psicologia questionava o seu papel e tentava desenvolver novas práticas. Na década de 90, a Associação Brasileira de 
Psicologia do Trânsito continuava ativa, sendo convocada, junto a outras entidades, pelas instâncias superiores do trânsito para discutir e avaliar o Sistema Nacional de Trânsito, conforme evidencia a Ata $n^{\circ} 3.681$, da $26^{a}$ reunião ocorrida no Ministério da Justiça: "ASSUNTOS GERAIS: Com a finalidade de colher subsídios para elaboração de um documento que contenha as informações sobre a situação do Sistema Nacional de Trânsito e as expectativas para os próximos tempos, o colegiado recebeu, em plenário, para falar sobre o assunto, os representantes seguintes: (...) 12 - Associação Brasileira de Psicologia do Trânsito (ABPT) Dr. RENIER ROZESTRACTEM (...)" (Diário Oficial, 1994, p. 15, grifos no original). Essa parece ser mais uma evidência da força da associação nacional na formulação de políticas públicas na área de trânsito.

Anos depois, em 1997, foi instituído o Código de Trânsito Brasileiro - CTB (Brasil, 2002), atualmente em vigor. Essa lei trouxe profundos avanços para a segurança viária com repercussões no comportamento do brasileiro, dentre os quais a redução das mortes no trânsito (Fundação Getúlio Vargas, 2007). Uma das novidades do documento foi a incorporação do tema educação como um dos elementos centrais para todos os participantes do trânsito. É importante destacar que o novo código repercutiu no trabalho do psicólogo antes mesmo de entrar em vigor. Na época em que era um projeto de lei, o Presidente da República Fernando Henrique Cardoso (1995-2003) vetou alguns artigos, inclusive o que indicava a obrigatoriedade do exame psicológico ao candidato à habilitação. As razões do veto foram as seguintes:

Países rigorosos no combate à violência no trânsito não adotam o exame psicológico para motoristas. Considerase que os exames fisico-mentais sejam suficientes para a análise da capacitação do candidato à habilitação. Os exames psicológicos poderão ser obrigatórios para os infratores contumazes, caso em que se torna necessária uma investigação mais detalhada do comportamento individual. Justifica-se, assim, vetar o inciso II do art. 147 (...) (http://www.planalto.gov.br/ ccivil_03/leis/Mensagem_Veto/anterior_98/ Mvep1056-97.htm)

Com relação a essa justificativa, parece injusto atribuir somente aos exames psicológicos a responsabilidade na diminuição dos acidentes de trânsito, mesmo que existam poucas evidências de que é possível predizer o comportamento infrator ou o acidente de trânsito a partir de alguns instrumentos psicológicos usados no processo de habilitação atualmente (e.g., Silva \& Alchieri, 2007, 2008, 2010). Os acidentes de trânsito possuem causas multifatoriais que precisam ser analisadas e que vão além do indivíduo (Rozestraten, 2001).

A mobilização e a articulação política dos psicólogos, do CFP e dos CRPs garantiram que o veto fosse suplantado por nova lei que incluiu o exame (ver Tabela 1), demonstrando a força política dos psicólogos. Algumas instituições e políticos advogaram a causa. Destaca-se, por exemplo, o discurso de um Senador da República, a 17 de outubro de 1997, no Senado Federal:

Seja do ponto de vista econômico, seja de saúde pública, os recursos preventivos superam em muito, em eficácia, qualquer providência tomada a posteriori. E uma medida antecipadora de futuros sinistros, de comprovada serventia, é a avaliação mental do candidato à Carteira Nacional de Habilitação. E, por seu caráter científico e seu enfoque especializado, de grande acuidade na detecção de desvios de personalidade, tendências agressivas ou distúrbios de psicomotricidade, e mesmo neurológicos, difíceis de surpreender ao exame clínico comum, o teste psicológico não pode deixar de integrar a avaliação mental do pretendente à condução de veículos automotores (Borges, 1997, p. 12, grifo no original) 
$\mathrm{O}$ argumento toma por base o aspecto preventivo do exame psicológico, conforme sugerem os psicólogos. O veto, de certa forma, repetiu algo que já acontecera no passado, com a mudança na redação do primeiro Código de Trânsito, na década de 1940, conforme explicitado na seção anterior. Desse modo, a discussão sobre a inclusão ou não dos exames psicológicos no processo de habilitação parece ser um acontecimento cíclico. Se esse raciocínio estiver correto, é provável que ela se repita na (re)elaboração dos próximos códigos. Caso isso de fato aconteça, quais argumentos utilizaremos?

Com a reinserção da avaliação psicológica no processo de aquisição da habilitação, o CONTRAN regulamentou este exame a partir da Res. n 51 (CONTRAN, 1998a), que dispunha sobre os exames de aptidão física e mental e os exames de avaliação psicológica (ver, na Tabela 2, um histórico de resoluções do CONTRAN sobre a avaliação em motoristas). Psicólogos participaram da elaboração desta e de outras resoluções relativas ao seu trabalho. Dentre as novidades dessa resolução, estavam algumas exigências para o credenciamento, como ter concluído o Curso de Capacitação para Psicólogo Perito Examinador (carga-horária de 120h).

Meses depois, essa resolução foi alterada pela Res. $n^{\circ} 80$ (CONTRAN, 1998b). Dentre as modificações relativas à resolução anterior, incluem-se a realização dos exames de avaliação psicológica na mudança de categoria de habilitação e a denominação das áreas a serem avaliadas: a) área perceptoreacional, motora e nível mental, b) área do equilíbrio psíquico e c) habilidades específicas, anteriormente denominadas área cognitiva, práxica e do equilíbrio psíquico. A descrição dos percentis mínimos e de outros parâmetros dos instrumentos estabelecidos por categoria não foi mantida. Os cursos de capacitação continuaram, sendo exigida, ainda, experiência mínima de um ano na área de avaliação psicológica para atuar como perito credenciado aos DETRANs. Esses cursos contribuíram para a formação/ reciclagem de muitos profissionais que há anos não se atualizavam, mas muitos deles se concentraram em algumas regiões, não sendo encontrados facilmente no Brasil, o que dificultou a formação de novos peritos. Simultaneamente, essa situação favoreceu clínicas e psicólogos de várias cidades à medida que tinham um mercado sem concorrência. Em parte por causa disso, após as capacitações, muitos profissionais não voltaram a se atualizar. A resolução também previu a realização de junta especial de saúde, constituída por três psicólogos com experiência na área de trânsito, para efetuar a reavaliação dos candidatos considerados inaptos que solicitassem revisão do processo. Embora se reconheça a importância dessas juntas, elas carecem atualmente de uma regulamentação que padronize e oriente os procedimentos e a organização das atividades dos psicólogos. Ela tem sido realizada de diferentes formas nos diversos Estados brasileiros, o que compromete a qualidade do trabalho. 
Tabela 2. Resoluções do CONTRAN que incidem no trabalho do psicólogo

Resoluções Assuntos

$\mathrm{n} \cong 51$, de 21 de maio de 1998

no 80 , de 19 de novembro de 1998

no 168 , de 14 de dezembro de 2004

no 267 , de 15 de fevereiro de 2008

no 283, de 01 de julho de 2008

no 327 , de 14 de agosto de 2009

no 300 , de 04 de dezembro de 2008
Dispõe sobre os exames de aptidão física e mental e os exames de avaliação psicológica

Altera os Anexos I e II da Res. n51/98-CONTRAN, que dispõe sobre os exames de aptidão física e mental e os exames de avaliação psicológica

Estabelece normas e procedimentos para a formação de condutores de veículos automotores e elétricos, a realização dos exames, a expedição de documentos de habilitação, os cursos de formação, especialização e reciclagem

Dispõe sobre o exame de aptidão física e mental, a avaliação psicológica e o credenciamento das entidades públicas e privadas

Altera a Res. no 267/2008, tendo sido alterado apenas o art. 18

Altera a Res. $n$ o 267, tendo sido alterada apenas a alínea "b" do inciso I do art. 16

Estabelece procedimento administrativo para submissão do condutor a novos exames para que possa voltar a dirigir quando condenado por crime de trânsito ou quando envolvido em acidente grave
3 Instância deliberativa dos Conselhos Federal e Regionais de Psicologia. Ela é subordinada às deliberações do Congresso Nacional de Psicologia (CNP). Ver Res. CFP $n^{\circ}$ $10 / 98$.
Vencida a luta política para suplantar o veto, a Psicologia institucionalizou as discussões que vinham ocorrendo sobre a ampliação da área e da atuação do psicólogo na década anterior no âmbito acadêmico, estimulada por alguns profissionais. Assim, foi organizado o I Fórum Nacional de Psicologia do Trânsito, realizado em 1999. Esse evento foi considerado um marco importante na elaboração de diretrizes para as políticas e normatizações do CFP e dos CRPs na área de trânsito, levando em conta o potencial da área em planejamento urbano e educação (CFP, 2000a). Convém destacar o papel desse fórum ao convocar os psicólogos para desenvolver novas práticas e se inserir em novos espaços de atuação. Foram estabelecidas as competências do psicólogo, algumas inovadoras para a época, com enfoque na atuação ampla e interdisciplinar, sugerindo, a partir disso, outras atividades profissionais, como, por exemplo: colaborar na elaboração e na implantação de ações de engenharia e de operação de tráfego, participar de equipes multiprofissionais no planejamento e na realização das políticas de segurança para o trânsito, auxiliar na elaboração e na implantação de programas de saúde, educação e segurança e prestar assessoria e consultoria aos órgãos públicos/privados de trânsito (CFP, 2000a). Decorridos 13 anos desse evento, muitas das competências explicitadas não fazem parte efetivamente das práticas da maior parte dos psicólogos (ver CFP, 2009a), embora tenham um valor pedagógico importante para indicar aos estudantes e profissionais o que se pode fazer.

No documento decorrente desse fórum, cujas propostas foram deliberadas pela Assembleia das Políticas, da Administração e das Finanças do Sistema Conselhos (APAF) ${ }^{3}$ - o Caderno de Psicologia 
do Trânsito e Compromisso Social -, a articulação entre Psicologia e políticas públicas de trânsito e transporte começou a ser pensada explicitamente. Algumas das propostas relativas à formação do psicólogo e à inserção em políticas públicas, foram: “(...) transformar o curso de capacitação (...) em especialização lato sensu de Psicologia do trânsito", "os atuais psicólogos com curso de capacitação, supracitado, poderão fazer a complementação da carga horária exigida para o título de especialista", "divulgar o Código de Trânsito Brasileiro e outras legislações para a organização e a participação nas políticas públicas de qualidade de vida e segurança no trânsito", "que os CRPs e CFP solicitem a inclusão do psicólogo em todos os organismos pertencentes ao Sistema Nacional de Trânsito, visando à representação da categoria na construção de políticas públicas de segurança do trânsito" (CFP, 2000a, p.15-16). As deliberações quanto às especializações só aconteceram em 2008, por meio da Res. no 267 (CONTRAN, 2008a). Porém, a complementação da carga horária não se tornou uma realidade.

Outro fruto das discussões do referido fórum foi a elaboração do Manual para Avaliação Psicológica de Candidatos à Carteira Nacional de Habilitação $(\mathrm{CNH})$ e condutores de veículos automotores (CFP, 2000b). Foi o primeiro manual dessa natureza publicado pelo Conselho Federal, e indicou as exigências mínimas de qualidade naquele trabalho (ver na Tabela 3 um histórico de resoluções do CFP sobre a avaliação em motoristas). O documento foi fruto de discussões no seio do CFP para adequar o trabalho do psicólogo às exigências das resoluções do CONTRAN, que regulamentavam os artigos referentes aos exames dos candidatos à $\mathrm{CNH}$ do Código de Trânsito, com repercussões na nossa profissão.

Tabela 3. Resoluções do CFP sobre a prática da avaliação psicológica em motoristas

\begin{tabular}{ll}
\hline $\begin{array}{l}\text { Resoluções e } \\
\text { nota técnica }\end{array}$ & Assuntos \\
\hline no 012/2000 & $\begin{array}{l}\text { Institui o Manual para Avaliação Psicológica de Candidatos à CNH e } \\
\text { Condutores de Veículos Automotores }\end{array}$
\end{tabular}

no 007/2009a Revoga a Res. CFP no 012/2000 e institui normas e procedimentos para avaliação psicológica no contexto do trânsito

no $009 / 2011$

Altera a Res. CFP no 007/2009

no 016/2002

Dispõe acerca do trabalho do psicólogo na avaliação psicológica de

candidatos

à Carteira Nacional de Habilitação e condutores de veículos automotores

으 06/2010

Altera a Res. CFP no 016/2002, que dispõe acerca do trabalho do psicólogo na avaliação psicológica de candidatos à Carteira Nacional de Habilitação e condutores de veículos automotores

O início do século XXI caracterizou-se, no plano político nacional, pela eleição do Presidente Luiz Inácio Lula da Silva (2003-2010). Nesse período, outras leis e normatizações afetaram o trabalho do psicólogo no que diz respeito ao seu trabalho de avaliar condutores de veículos automotores. Em 2001, por exemplo, foi promulgada a Lei n 10.350 (Brasil, 2001), que estabeleceu que a 
avaliação psicológica deveria ser realizada no ato de renovação sempre que o condutor se submeter o condutor que exerce atividade remunerada ao veículo.

Em 2004, entrou em vigor a Res. CONTRAN $n^{\circ} 168$, que estabelece, dentre outras coisas, normas e procedimentos para a realização dos exames para a habilitação. De acordo com o documento, o processo de habilitação do condutor, após o devido cadastramento dos dados informativos do candidato no Registro Nacional de Condutores Habilitados (RENACH), seguirá com a realização da avaliação psicológica, exame de aptidão física e mental, curso teórico-técnico, exame teórico-técnico, curso de prática de direção veicular e exame de prática de direção veicular, nessa ordem. Apesar disso, na prática, existem variações (incorretas) nessa ordem dos exames, por exemplo, nos casos em que a avaliação médica é feita antes da psicológica. A resolução estabelece ainda que a avaliação psicológica será exigida quando da: obtenção da autorização para conduzir ciclomotor (ACC) e obtenção da $\mathrm{CNH}$; renovação caso o condutor exerça serviço remunerado de transporte de pessoas ou bens; substituição do documento de habilitação obtido em país estrangeiro, ou por solicitação do perito examinador.

No plano institucional da Psicologia, o CFP intensificou suas ações no sentido da inserção do psicólogo em políticas públicas. Isso fica evidente nas frases do então presidente do CFP à época:

O Il Seminário de Psicologia e Políticas Públicas resulta do caráter estratégico das políticas para o futuro da profissão de psicólogo. Nesse contexto, e com as mudanças ocorridas desde a promulgação da Constituição de 1988, surge um novo dilema: ou os psicólogos envolvem-se com a construção de políticas públicas ou não terão perspectiva de futuro com a profissão no Brasil (Silva, 2003, p. 6)
Nessa ocasião, foi discutido o protagonismo social da Psicologia no campo da circulação humana. Na conferência, tentou-se colaborar para ampliar a intervenção da Psicologia do trânsito, inserindo-o em uma discussão mais ampla relacionada à vida social, à dimensão afetiva dos espaços de circulação (Silva, 2003).

Uma das expressões da estratégia do CFP foi o surgimento do Centro de Referências Técnicas em Psicologia e Políticas Públicas (CREPOP), em 2006, com o objetivo de consolidar a produção de referências para atuação dos psicólogos em políticas públicas, por meio de pesquisas realizadas nos diversos Estados. No caso do trânsito, o CREPOP realizou, recentemente, uma pesquisa nacional que evidenciou a participação dos psicólogos eminentemente na política de trânsito por meio da avaliação em (futuros) motoristas e o desconhecimento da maior parte dos respondentes sobre os marcos lógicos e legais relacionados a trânsito, transporte e mobilidade urbana (CFP, 2009a) ${ }^{4}$, o que precisa ser superado.

Outra iniciativa que o CFP buscou para construir e consolidar a participação da Psicologia no âmbito da política pública foi o Movimento Nacional pela Democratização no Trânsito, que expressou "o desejo da sociedade civil em construir políticas públicas voltadas para o trânsito que contemplem uma discussão crítica, democrática e transparente de forma intersetorial, interinstitucional e interdisciplinar" (http://www.mndt. org.br/quemsomos.cfm). O movimento, criado em 2007, e formado inicialmente por 27 instituições que trabalham direta ou indiretamente com o tema, buscou desenvolver ações que objetivam a mobilidade, a cidadania, a saúde e a paz no trânsito; contudo, ao que parece, encontra-se atualmente desarticulado.

Em 2008, o CONTRAN emitiu a Res. $n^{\circ}$ 300 , que estabeleceu o procedimento 
administrativo nos casos em que o condutor foi condenado por crime de trânsito ou se envolveu em acidente grave, devendo submeter-se a novos exames para que pudesse voltar a dirigir, incluindo a avaliação psicológica.

Ainda nesse ano, entrou em vigor a Res. $n^{\circ} 267$ (CONTRAN, 2008b, 2009), que estabelece os seguintes processos psíquicos a serem avaliados: tomada de informação, processamento de informação, tomada de decisão, comportamento, autoavaliação do comportamento e traços de personalidade. Quanto ao resultado da avaliação, o candidato poderá ser considerado: apto, inapto temporário ou inapto. A resolução anterior previa que o candidato poderia ser considerado, além desses resultados, apto com restrição. A junta psicológica foi mantida. No credenciamento, dentre as mudanças, destaca-se a necessidade de se ter, no mínimo, dois anos de formado; além disso, estabeleceu que a carga horária do curso de perito seria aumentada para $180 \mathrm{hs}$ e que, a partir de 2013, só serão credenciados os psicólogos portadores de título de Especialista em Psicologia do Trânsito reconhecido pelo CFP. Várias especializações têm sido criadas em todo o País, e vários psicólogos estão voltando para se atualizar (ver Silva \& Günther, 2009 para uma discussão crítica sobre essa questão). Vale ressaltar que essa era, conforme apresentado anteriormente, uma proposta do I Fórum Nacional de Psicologia do Trânsito, deliberada pela APAF em 2000. Atualmente, o CONTRAN analisa a possibilidade de estabelecer um prazo maior a partir do pleito dos psicólogos (e.g., até 2015), contudo, até o momento, ainda não existe um posicionamento oficial sobre esse ponto.

Em 2009, o CFP publicou nova resolução que revogava a Res. no 012 (CFP, 2000b) e que instituiu novas normas e procedimentos para a avaliação psicológica no contexto do trânsito (CFP, 2009b). Essa resolução foi concebida para orientar os psicólogos em função da Res. n 267 (CONTRAN, 2008a).

Em três de junho de 2011, foi criada a Rede Latino-Americana de Psicologia do Trânsito (Relapsitran) $^{5}$, uma iniciativa cujo objetivo é fomentar o intercâmbio de conhecimentos, informações e ideias entre profissionais e pesquisadores de Psicologia e de outras áreas de conhecimento. A rede tem a perspectiva de contribuir para disseminar a Psicologia do trânsito nos países latino-americanos, promovendo seu desenvolvimento científico e profissional, conta atualmente com 90 participantes em diversos Estados brasileiros, psicólogos e não psicólogos, além de psicólogos de outros países, como Argentina, Chile e México. São assuntos recorrentes na Relapsitran o compartilhamento de referências bibliográficas, de eventos e de experiências profissionais.

Em síntese, conforme apresentado, o trabalho do psicólogo do trânsito tem sido orientado por decretos-lei, leis, resoluções e portarias provenientes de várias instituições. No seio dos DETRANs e das clínicas, a Psicologia construiu o seu espaço e segue seu itinerário, cujas bases foram lançadas na época do primeiro Código de Trânsito. Anos depois, nas décadas de 80 e 90, a Psicologia do trânsito teve bastante influência nas instâncias de decisão da política pública de trânsito. No século XXI, a Psicologia do trânsito conseguiu consolidar a sua participação no processo de habilitação, superando movimentos contrários à sua obrigatoriedade, e simultaneamente, vem buscando ampliar o foco das suas intervenções além do motorista, envolvendo-se com políticas públicas, embora ainda a passos lentos. Em 50 anos de regulamentação da Psicologia no Brasil, portanto, o quê podemos comemorar e o quê podemos aprimorar? 


\section{0 anos de profissão no Brasil: o que comemorar e o que aprimorar?}

Neste artigo, foram analisados 50 anos de Psicologia do trânsito, contemplando alguns aspectos históricos relevantes no período pré e pós-regulamentação da profissão, indicando as raízes mais antigas dessa área. É oportuno destacar que outros acontecimentos e outras políticas implementadas ao longo desse tempo influenciaram a Psicologia do trânsito de alguma maneira e vice-versa (e.g., Nascimento \& Garcia, 2009). No presente estudo, em um esforço de síntese histórica, buscou-se contemplar acontecimentos importantes para pensar sobre o passado e que possibilite planejar o futuro da área, especialmente relacionados à avaliação psicológica em motoristas.

A partir da análise exposta, do ponto de vista profissional e político, em que pesem as tentativas de veto nos Códigos de Trânsito anteriores, há que comemorar a continuidade da avaliação psicológica no processo de habilitação de (futuros) motoristas na política de trânsito, assim como a participação da Psicologia em instâncias consultivas ou decisivas das políticas de trânsito (e.g., nas câmaras temáticas do CONTRAN). Devemos comemorar também as oportunidades de formação profissional, como as especializações específicas em Psicologia do trânsito, um fenômeno recente que, embora seja uma obrigatoriedade, tem promovido, simultaneamente, a atualização de profissionais que há anos não o faziam e a abertura de novas perspectivas para quem nunca teve a oportunidade de estudar trânsito na graduação, como também a ampliação do mercado para exercer a docência. Assim, espera-se que os futuros especialistas possam abrir caminhos na participação em outras políticas de trânsito, transporte e mobilidade, assim como na ocupação de novos espaços de trabalho além das clínicas e dos DETRANs.
Merecem comemoração alguns esforços do CFP e CRPs para discutir e qualificar ações dos profissionais a partir, por exemplo, dos seminários, debates, livros e seminários, debates, livros e relatórios (e.g., CFP, 2010), apesar da necessidade de um investimento ainda maior junto à categoria nos problemas enfrentados no dia a dia, na fiscalização, no fomento à criação de grupos de pesquisa nas universidades e à discussão de temas relativos à Psicologia do trânsito na graduação, assim como na promoção de maior articulação entre as comissões de Psicologia do trânsito dos CRPs. Merece destaque, por exemplo, a elaboração de Referências Técnicas para a Prática de Psicólogos em Políticas de Mobilidade Urbana, Transporte e Trânsito, que em breve estarão disponíveis para os psicólogos. Espera-se que o documento espelhe o que acontece na prática atual dos psicólogos do trânsito, mas também que aponte diretrizes para a atuação desses profissionais nas políticas públicas que incidem sobre a diminuição do transporte motorizado e suas decorrências negativas. A seguir, sugere-se alguns aspectos que podemos e/ou devemos aprimorar no âmbito da formação, da profissão e da ciência.

Na formação (graduação e pós), deve-se estimular o conhecimento e a discussão das políticas públicas de trânsito e do debate das leis e resoluções, dentre outros documentos, como relatórios técnicos e pesquisas científicas, seja durante as aulas, palestras, seja cursos. Além disso, o estudante deverá desenvolver competências para trabalhar em equipes multiprofisisonais e estreitar relações intersetoriais junto às organizações que lidam com as políticas públicas de trânsito, transporte e mobilidade urbana. O desafio na graduação consiste principalmente em atrair a atenção dos alunos para discutir o tema trânsito, ainda mais quando a Psicologia do trânsito, embora com raízes antigas, é considerada nova ou emergente, assim justificando-se, em alguns 
Na ciência,

é necessário

ampliar as

pesquisas sobre

validade preditiva

dos testes

psicológicos

usados na

habilitação de

motoristas, uma

vez que poucos

estudos tem se

dedicado a este

tema; ou seja,

deve-se buscar

estabelecer

relações entre

o desempenho

em um teste e o

comportamento

no trânsito, a fim

de identificarmos

com maior

clareza qual a

contribuição

desta exigência

na segurança

viária (ver Silva \&

Alchieri, 2010). casos, a ausência completa de conteúdos a ela relacionados nas várias disciplinas dos cursos ou uma abordagem superficial do tema, o que deve ser superado. Na pósgraduação, notadamente nas especializações, o desafio é estimular a produção científica de qualidade dos cursos para que as monografias possam ser publicadas como artigos, o que ajudará a ampliar a literatura da área. Em muitos casos, as monografias objetivam simplesmente cumprir uma "etapa burocrática" para a aquisição do título de especialista; porém, isso não contribui com o avanço científico. Alunos e profissionais devem ser estimulados a continuarem sua formação, por exemplo, fazendo mestrado e doutorado, que possibilitam uma atuação ainda mais sólida ao psicólogo, do ponto de vista teórico e metodológico.

Na profissão, deve-se estimular a maior participação e envolvimento dos psicólogos nos fóruns, conferências e discussões que visam à formulação, ao acompanhamento ou avaliação das políticas públicas de trânsito. Essa também é uma forma de atualizar-se e de conhecer as próximas etapas da política. Além disso, os psicólogos devem articular a criação e o fortalecimento contínuo de associações científicas e profissionais de Psicologia do trânsito. É possível tornar fortes essas associações (algumas já existentes no âmbito dos estados), pois são importantes para representar a categoria nas instâncias de decisão, sendo maior a possibilidade de os psicólogos obterem êxito em suas propostas ao buscar articulação junto a outras entidades nacionais e internacionais. A Rede Latino-Americana de Psicologia do Trânsito (Relapsitran) pode ser um dos caminhos para isso. Por meio das associações, é possível também colaborar para promover melhores condições de trabalho para os psicólogos que atuam, por exemplo, nas clínicas e nos DETRANs (e.g., ter autonomia na escolha dos instrumentos psicológicos a serem usados na avaliação), e para que o trabalho do psicólogo seja melhor definido e orientado de acordo com as suas necessidades profissionais e de acordo com as necessidades sociais. Outro aspecto profissional a ser aprimorado é o compartilhamento de experiências (bem ou malsucedidas), a fim de que o psicólogo colabore para a produção de conhecimento. Sem esse intercâmbio, o aperfeiçoamento do trabalho na execução da política pública, por exemplo, torna-se mais lento. Além disso, deve-se reivindicar a constante atualização e/ ou elaboração de resoluções que incidem no trabalho do psicólogo do trânsito (e.g., trabalho nas juntas psicológicas), sem prejudicar a sua autonomia e o trabalho correto.

Na ciência, é necessário ampliar as pesquisas sobre validade preditiva dos testes psicológicos usados na habilitação de motoristas, uma vez que poucos estudos tem se dedicado a este tema; ou seja, deve-se buscar estabelecer relações entre o desempenho em um teste e o comportamento no trânsito, a fim de identificarmos com maior clareza qual a contribuição desta exigência na segurança viária (ver Silva \& Alchieri, 2010). Além disso, é necessário subsidiar a ampliação da perspectiva de atuação do psicólogo do trânsito. A produção de conhecimento deve orientar os psicólogos a atuar de uma forma mais embasada e eficaz. Os psicólogos precisam criar formas de desenvolver suas intervenções com base também em outros modelos de atuação, além do que já existe. Algumas críticas ao modelo atual que enfatiza um enfoque observacional-classificatório é que sua raiz remete aos primórdios da Psicologia científica (Monterde, 1987), isto é, grande parte dos psicólogos do trânsito limitase a avaliar e a classificar as respostas dos candidatos para decidir se eles devem obter ou renovar sua habilitação. Em consonância com essa perspectiva, a segurança ao volante estaria à mercê fundamentalmente do nível de habilidade do condutor para adaptar-se às exigências que as diferentes situações de circulação the impõem (Carbonell, Bañuls, 
Cortés, \& Sáiz, 1995). Para os próximos anos, os psicólogos do trânsito devem buscar implementar também um modelo intervencionista não só junto aos motoristas, como também nos usuários mais vulneráveis do trânsito (e.g., pedestres e ciclistas). A tônica neste modelo é a intervenção nos processos humanos para tentar modificálos, considerando os fenômenos observados como determinados pelo momento e pelo ambiente social (Monterde, 1987). Isso implica a adoção de outras teorias e conceitos que têm sido estudados e/ou aplicados, especialmente no contexto internacional, aos problemas do trânsito para produzir intervenção na segurança. Exemplos disso são os modelos congnito-motivacionais que destacam o papel ativo do sujeito que é capaz de redefinir os planos de conduta em função do contexto, e não apenas reagir a ele. Com esses modelos, a investigação passa a centrar-se nas expectativas e nas motivações, por exemplo, do condutor, nos seus estados emocionais, valores e normas pessoais e suas influências na percepção subjetiva de risco, assim como na sua relação com a tolerância ao risco na hora de tomar decisões (Carbonell et al., 1995). Alguns exemplos próprios da Psicologia do trânsito para explicar o comportamento do motorista, são: o modelo de risco zero (Näätänen \& Summala, 1974), a teoria da homeostase de risco (Wilde, 2005) e o modelo de evitação da ameaça (Fuller, 1984). Não se tem registro, na literatura nacional, do teste destes modelos explicativos. Talvez um dos grandes desafios na área de trânsito, até o aniversário do centenário da regulamentação da Psicologia no Brasil, seja justamente aprimorar a atuação profissional incorporando esses ou outros modelos, embasando cientificamente a execução, o acompanhamento, a avaliação ou a elaboração de políticas públicas de trânsito com base na Psicologia, a fim de intervirmos com qualidade junto ao comportamento dos usuários do trânsito e do transporte. 


\section{Referências}

Alchieri, J. C., \& Stroeher, F. (2002). Avaliação psicológica no trânsito: o estado da arte no Brasil sessenta anos depois. In R. M. Cruz, J. C. Alchieri \& J. Sardá (Eds.), Avaliação e medidas psicológicas (pp. 234-345). São Paulo: Casa do Psicólogo.

Amorim, J. A. (1953). Normas para a prova do tacodômetro. Arquivos Brasileiros de Psicotécnica, 5(3), 33-36.

Antipoff, D. (1956). Contribuição ao estudo das diferenças individuais no teste de atenção difusa. Arquivos Brasileiros de Psicotécnica, 8(2), 49-60.

Antunes, M. A. M. (2001). A psicologia no Brasil: leitura histórica de sua constituição. São Paulo: EDUC/UNIMARCO.

Borges, G. (1997, 17 de out.). Pronunciamentos. Senado Federal. Recuperado em 01 de abril de 2012 de http://www.senado. gov.br/atividade/pronunciamento/detTexto.asp?t=215484

Brasil. (1941). Decreto-lei n. 3.651 - de 25 de setembro de 1941. Dá nova redação ao Código Nacional de Trânsito. Recuperado em 01 de abril, 2012 de http://www6.senado. gov.br/legislacao/ListaNormas.action?numero=3651\&tipo_ norma $=$ DEL\&data $=19410925 \&$ link $=\mathrm{s}$

Brasil. (1946). Decreto-lei n. 9.545 - de 05 de agôsto de 1946 Dispõe sôbre a habilitação e exercício da atividade de condutor de veículos automotores. Recuperado em 01 de abril, 2012 de http://www2.camara.gov.br/legin/fed/declei/1940-1949/ decreto-lei-9545-5-agosto-1946-417705-publicacaooriginal1-pe.html

Brasil. (1966). Lei $n^{\circ}$ 5.108, de 21 de setembro de 1966. Institui o Código Nacional de Trânsito. Recuperado em 01 de abril, 2012 de https://www.planalto.gov.br/ccivil_03/Leis/19501969/L5108impressao.htm

Brasil. (1981). Decreto $n^{\circ}$ 86.714, de 10 de dezembro de 1981. Promulga a Convenção sobre Trânsito Viário. Recuperado em 01 de abril de 2012 de http://www.jusbrasil.com.br/ legislacao/114637/decreto-86714-81

Brasil. (1994, 12 de dezembro). Ata $n^{\circ}$ 3.681, da $26^{a}$ reunião de 1994. Diário Oficial da União. Seção 1, Recuperado em 01 de abril, 2012 de http://www.jusbrasil.com.br/ diarios/1420346/dou-secao-1-12-12-1994-pg-15
Brasil. (2001). Lei $n^{\circ}$ 10.350, de 21 de dezembro de 2001. Altera a Lei $n^{\circ}$ 9.503, de 23 de setembro de 1997 - Código de Trânsito Brasileiro, de forma a obrigar a realização de exame psicológico periódico para os motoristas profissionais. Recuperado em 01 de abril, 2012 de https://www.planalto.gov.br/ccivil_03/leis/ leis_2001/l10350.htm

Brasil. (2002). Código de Trânsito Brasileiro. Brasília, DF: Senado Federal.

Campos, F. (1951). Seleção psicotécnica de motoristas. Arquivos Brasileiros de Psicotécnica, 3(3), 7-26.

Carbonell, E. J., Bañuls, R., Cortés, M. T., \& Sáiz, E. J. (1995). El comportamiento humano en la conducción: modelos explicativos. In L. Montoro, E. J. Carbonell, J. Sanmartín \& F. Tortosa (Eds.), Seguridad vial: del fator humano a las nuevas tecnologías (pp. 164-201). Madrid: Síntesis.

Conselho Federal de Psicologia. (1986). Psicologia do trânsito. Psicologia: Ciência e Profissão, 6(2). 18.

Conselho Federal de Psicologia. (1998). Resolução CFP $n^{\circ}$ 10/98. Institui o regimento interno da assembleia das políticas administrativas e financeiras. Brasília, DF: Autor.

Conselho Federal de Psicologia. (2000a). Caderno de psicologia do trânsito e compromisso social. Brasília, DF: Autor.

Conselho Federal de Psicologia. (2000b). Resolução CFP n. ${ }^{\circ}$ 012/00. Institui o Manual para Avaliação Psicológica de Candidatos à Carteira Nacional de Habilitação e Condutores de Veículos Automotores. Brasília, DF: Autor.

Conselho Federal de Psicologia. (2009a). Atuação dos psicólogos em políticas públicas de mobilidade urbana, transporte e trânsito: relatório descritivo preliminar de pesquisa. Brasília, DF: Autor.

Conselho Federal de Psicologia. (2009b). Resolução CFP $n^{\circ}$ 007/2009. Revoga a Resolução CFP n ${ }^{\circ} 012 / 2000$, publicada no DOU do dia 22 de dezembro de 2000, Seção I, e institui normas e procedimentos para a avaliação psicológica no contexto do trânsito. Brasília, DF: Autor.

Conselho Federal de Psicologia. (2010). Seminário nacional psicologia e mobilidade: espaço público como direito de todos. Brasília, DF: Autor. 
Conselho Nacional de Trânsito. (1998a). Resolução $n^{\circ}$. 51, de 21 de maio de 1998. Dispõe sobre os exames de aptidão física mental e os exames de avaliação psicológica a que se refere o inciso I, do art. 147 do Código de Trânsito Brasileiro e os \$§ 3 e $4^{\circ}$ do art. $2^{\circ}$ da Lei 9.602/98. Brasília, DF: Autor.

Conselho Nacional de Trânsito. (1998b). Resolução n 80, de 19 de novembro de 1998, que altera os Anexos I e II da Resolução $n^{\circ}$ 51/98-CONTRAN, que dispõe sobre os exames de aptidão física e mental e os exames de avaliação psicológica. Brasília, DF: Autor.

Conselho Nacional de Trânsito. (2004). Resolução no 168, de 14 de dezembro de 2004. Estabelece normas e procedimentos para a formação de condutores de veículos automotores e elétricos, a realização dos exames, a expedição de documentos de habilitação, os cursos de formação, especializados, de reciclagem e dá outras providências. Brasília, DF: Autor.

Conselho Nacional de Trânsito. (2008a). Resolução $n^{\circ}$ 267, de 15 de fevereiro de 2008. Dispõe sobre o exame de aptidão física e mental, a avaliação psicológica e o credenciamento das entidades públicas e privadas de que tratam o art. 147 , I e $\S \S 1^{\circ}$ a $4^{\circ}$ e o art. 148 do Código de Trânsito Brasileiro. Brasília, DF: Autor.

Conselho Nacional de Trânsito. (2008b). Resolução $n^{\circ} 283$ de $01^{\circ}$ de julho de 2008. Altera a Resolução $n^{\circ} 267$, de 15 de fevereiro de 2008, do CONTRAN, que dispõe sobre o exame de aptidão física e mental, a avaliação psicológica e o credenciamento das entidades públicas e privadas de que tratam o art. 147, I e $\$ \S 1^{\circ}$ e $4^{\circ}$ e o art. 148 do Código de Trânsito Brasileiro - CTB. Brasília, DF: Autor.

Cristo, F. (2011). Departamento de trânsito (DETRAN). In A. M. Jacó-Vilela (Ed.), Dicionário histórico de instituições da psicologia no Brasil (pp. 177-179). Rio de Janeiro: Imago.

Departamento Nacional de Trânsito. (2010). 100 anos de legislação de trânsito no Brasil. Brasília, DF: Ministério das Cidades.

Empresa Brasileira de Planejamento de Transportes. (1987). O acidente de tráfego: flagelo nacional evitável. Brasília, DF: Autor.

Fuller, R. (1984). A conceptualization of driving behaviour as threat avoidance. Ergonomics, 27(11), 1139-1155.

Fundação Getúlio Vargas. (2007). O estado da juventude: drogas, prisões e acidentes. Rio de Janeiro: FGV/IBRE.

Instituto de Pesquisa Econômica Aplicada. (2010). Infraestrutura social e urbana no Brasil: subsídios para uma agenda de pesquisa e formulação de políticas públicas. Brasília, DF: Autor.

Lima Neto, O. (2001). Transporte no Brasil: história e reflexões. Brasília, DF: Empresa Brasileira de Planejamento de Transportes/GEIPOT. Recife: Editora Universitária da UFPE.

Monterde, H. (1987). La evaluación psicológica por medio del ordenador: validez de constructo y fiabilidad de las actuales pruebas psicológicas para conductores basadas en ordenador. Revista de Psicología del Trabajo y de las Organizaciones, 3(6), 29-47.

Näätänen, R., \& Summala, H. (1974). A model for the role of motivational factors in drivers' decision-making. Accident Analysis and Prevention, 6, 243-261.

Nascimento, A. S., \& Garcia, M. L. T. (2009). Álcool e direção: uma questão na agenda política brasileira. Psicologia \& Sociedade, 21(2), 213-222.

Nava, J. (Ed.) (1957). Aspectos da personalidade em seleção de condutores de veículos. Belo Horizonte: Itatiaia.

Nava, J., \& Cunha, S. E. (1958). Atenção difusa em trabalhos automatizáveis e variáveis. O teste de Lahy, sem projeção cinematográfica, e a padronização dos resultados $(3.000$ casos). Arquivos Brasileiros de Psicotécnica, 10(1/2), 79-101.
Rozestraten, R. J. A. (1988b). Psicologia do trânsito: conceitos e processos básicos. São Paulo: E.P.U.

Rozestraten, R. J. A. (2001). Os prós e contras da análise de acidentes de trânsito. Arquivos Brasileiros de Psicologia, 53(3), 7-22

Rozestraten, R. J. A., \& Dotta, A. J. (1996). Os sinais de trânsito e o comportamento seguro (2a ed.). Porto Alegre: Sagra Luzzatto.

Rozestraten, R. J. A. (1981). Psicologia do trânsito; o que é e para que serve. Psicologia: Ciência e Profissão, 1(1), 141-143.

Rozestraten, R. J. A. (1982). A opinião de psicólogos brasileiros sobre o exame psicológico para motorista no Brasil. Anais da XII Reunião Anual de Psicologia, (pp. 105-117). Ribeirão Preto, SP.

Rozestraten, R. J. A. (1983). A psicologia do trânsito: sua definição e área de ação. Psicologia \& Trânsito, 1(1), 6-19.

Rozestraten, R. J. A. (1985). O exame psicológico para motorista em alguns países fora do Brasil. Psicologia \& Trânsito, 2(2), 67-74.

Rozestraten, R. J. A. (1988a). Curso de pós-graduação em psicobiologia. In A. D. Schliemman \& J. T. R. Falcão (Eds.), Anais do $1^{\circ}$ Simpósio Brasileiro de Pesquisa e Intercâmbio Científico da Anpepp (pp. 127-131). Rio de Janeiro: ANPEPP.

Silva, F. H. V. C. \& Alchieri, J. C. (2007). Avaliação psicológica da personalidade de condutores: uma revisão de literatura. Psico-USF, 12(2), 189-196.

Silva, F. H. V. C., \& Alchieri, J. C. (2008). Revisão das pesquisas brasileiras em avaliação psicológica de habilidades e inteligência de condutores. Estudos de Psicologia, 13(1), 57-64.

Silva, F. H. V. C., \& Alchieri, J. C. (2010). Validade preditiva de instrumentos psicológicos usados na avaliação psicológica de condutores. Psicologia: Teoria e Pesquisa, 26(4), 695-706.

Silva, F. H. V. C., \& Günther, H. (2009). Psicologia do trânsito no Brasil: de onde veio e para onde caminha? Temas em Psicologia, 17(Esp. 1), 163-175.

Silva, M. V. O. (Ed.). (2003). II Seminário de Psicologia e Políticas Públicas: Relatório. Brasília, DF: CFP.

Spagnhol, J. M. (1985). A psicologia do trânsito no Brasil: desenvolvimento e perspectivas. Psicologia \& Trânsito, 2(2), 7-10

Vieira, M. V. M., Pereira, A. O., \& Carvalho, A. V. (1953). O exame psicotécnico de motoristas no Distrito Federal. Arquivos Brasileiros de Psicotécnica, 5(4), 41-50.

Wilde, G. J. S. (2005). O limite aceitável de risco: uma nova psicologia de segurança e de saúde. São Paulo: Casa do Psicólogo. 